Full length article

\title{
Risk factors for sporadic cryptosporidiosis: A systematic review and meta- analysis
}

\author{
Pauline Kooh $^{\mathrm{a}, *}$, Anne Thébault ${ }^{\mathrm{a}}$, Vasco Cadavez ${ }^{\mathrm{b}}$, Ursula Gonzales-Barron ${ }^{\mathrm{b}}$, Isabelle Villena ${ }^{\mathrm{c}}$ \\ ${ }^{\text {a }}$ Risk Assessment Department, French Agency for Food, Environmental and Occupational Health and Safety (ANSES), Maisons-Alfort, France \\ ${ }^{\mathrm{b}}$ Centro de Investigação de Montanha (CIMO), Instituto Politécnico de Bragança, Bragança, Portugal \\ ${ }^{\mathrm{c}}$ Laboratory of Parasitology-Mycology, EA ESCAPE, University of Reims Champagne-Ardenne, Reims, France
}

\section{A R T I C L E I N F O}

\section{Keywords:}

Research synthesis

Case-control studies

Cohort studies

Meta-regression

Cryptosporidium

\begin{abstract}
A B S T R A C T
Cryptosporidium spp. is an important cause of gastrointestinal disease worldwide, responsible for 69 million case of illness in 2016. Information on the sources and transmission pathways of human cryptosporidiosis results mainly from outbreak investigations.

A systematic review and a meta-analysis of case-control and cohort studies were performed to determine the main risk factors associated with sporadic cryptosporidiosis. Suitable scientific articles were identified through a systematic literature search and subjected to a methodological quality assessment. From each study, odds ratio (OR) measures were extracted or calculated, as well as study characteristics such as population type, design, type of model and risk factor hierarchy. Mixed-effects meta-analysis models were adjusted by population type to appropriate data partitions.

From 1985 identified references, the quality assessment stage was passed by 57 cohort and case-control studies focusing on sporadic cryptosporidiosis. The eligible studies were conducted between 1983 and 2016 and provided 568 OR categorized for meta-analysis.

This meta-analysis identified travel, immunocompromising conditions, contact with infected humans, waterborne transmission (contact with recreational waters, wastewater, and consumption of untreated drinking water), contact with animals and food consumption as the relevant risk factors for sporadic cryptosporidiosis. With regards to food exposures, consumption of meat, dairy products (raw milk) and dishes consumed outside home were found significantly associated with cryptosporidiosis. The consumption of poorly washed fruits and vegetables significantly increases ORs. This meta-analysis reveals that some potential sources of Cryptosporidium such as shellfish or vegetables are under-investigated.

Future case-control studies for sporadic cryptosporidiosis should include population at risk, and investigate other potential sources in relation to the genotype and the subtype of Cryptosporidium spp.
\end{abstract}

\section{Introduction}

Cryptosporidium spp. is a protozoan parasite that belongs to Apicomplexa phylum. Cryptosporidium spp. is a well-known causative agent of gastrointestinal diseases and commonly identified in humans and animals, including livestock and particularly cattle (calves). The main symptom of human cryptosporidiosis is diarrhea that may be responsible for weight loss and dehydration in immunocompetent, but immunocompromised patients are at increased risk of developing a severe disease (Hunter and Nichols, 2002).

Cryptosporidium spp. are globally distributed, responsible for 69 million cases of illness, and 57,203 deaths in 2016 (Troeger et al.,
2018). Kirk et al. (2015) estimated that cryptosporidiosis resulted in 2159,331 DALYs in 2010. A clinical and epidemiological study involving 22,500 children from Africa and Asia revealed that Cryptosporidium spp. is one of four pathogens responsible for most of moderate to severe diarrhea in infants and toddlers (Kotloff et al., 2013). In 2016, Cryptosporidiosis was estimated to account for $10 \%$ of cases of diarrhea mortality among children under 5 years old (Troeger et al., 2018).

There are numerous species and genotypes of Cryptosporidium, but human infection involves mainly two species: Cryptosporidium hominis, whose main host is humans and Cryptosporidium parvum which infects animal and ruminants. Transmission can occur through the fecal-oral route, involving direct (person-to-person transmission or contact with

\footnotetext{
* Corresponding author.

E-mail addresses: pauline.kooh@anses.fr (P. Kooh), anne.thebault@anses.fr (A. Thébault), vcadavez@ipb.pt (V. Cadavez), ubarron@ipb.pt (U. Gonzales-Barron), ivillena@chu-reims.fr (I. Villena).
} 
animals) and indirect (waterborne or foodborne) pathways.

Water is the principal vector of contamination of Cryptosporidium and, numerous waterborne outbreaks involving both drinking water and recreational waters have been reported (Moreira and Bondelind, 2017; Ryan et al., 2017). Over the past years, foodborne outbreaks of cryptosporidiosis have been increasingly reported involving a diversity of food products (Ryan et al., 2018). Outbreaks investigations provide useful information about sources and transmission pathways of human cryptosporidiosis. Nevertheless, cryptosporidiosis cases are underreported or underdiagnosed in most countries (ECDC, 2019; Haagsma et al., 2013).

Several epidemiological studies of sporadic cryptosporidiosis have been published. A systematic review and a meta-analysis of case-control and cohort studies were performed to determine the main risk factors associated with sporadic cryptosporidiosis. Characterization of risk factors will contribute to identifying measures to reduce the burden of cryptosporidiosis.

\section{Material and methods}

The protocol of the systematic review and the meta-analysis model are described in depth in the methodological paper of this special issue (Gonzales-Barron et al., 2019).

\subsection{Systematic review}

The literature search was conducted in March 2017 using a combination of keywords related to (1)"Cryptosporidium" "OR" "cryptosporidiosis", (2) "case-control" "OR" "risk factor" "OR" "cohort" (3) "infection" "OR" "disease", joined by the logical connector "AND". Relevant studies were identified from five bibliographic search engines, Science Direct, PubMed, Scielo, ISI Web of Science and Scopus. No restrictions were defined for the year of the study or type of publication. The search was limited to the languages English, French, Portuguese and Spanish.

Each reference record was screened for relevance for inclusion in the meta-analysis study. The methodological quality of the "candidate" studies was assessed using pre-set quality criteria, comprising (1) appropriate selection of the controls; (2) adjustment to correct for confounders, (3) comparability between cases and controls, (4) acceptable responses rates for the exposed and control groups; (5) data analysis appropriate to the study design; (6) provision of odds ratio (OR) with confidence interval or p-value; or provision of sufficient data to calculate ORs; overall quality of the study (Gonzales-Barron et al., 2019). Primary studies that passed the screening for relevance were marked as having a potential for bias if they failed to meet at least one of the methodological quality assessment criteria.

Data from primary studies were then extracted using a standardized spreadsheet. Data extracted included the relevant study characteristics (location, period, population, case definition, design, sample size of the groups, type of model, etc.), the categorized risk factors, the setting, the handling practices and the outcome of the study (ORs).

A data categorization scheme was established to hierarchically group the risk factors into travel, host-specific factors and, pathways of exposure (i.e., person-to-person, animal, environment, and food routes) (see the methodological paper of this issue). In addition to the standard risk factors, the class "Hygiene" (e.g. "no handwashing after toilet", "poor hygiene habits") was also used. Person-to-person transmission was stratified in three classes: contact in the household, contact in the community and sexual transmission. The variable "Population" was stratified into mixed (adults or undefined), children (under 16 years old) and susceptible (HIV infection, AIDS, elderly population).

\subsection{Data synthesis}

The joint meta-analytical data was first described using basic statistics. Next, data was partitioned into subsets of categories of risk factors. The meta-analytical models were then fitted to each of the data partitions or subsets to estimate pooled OR related to travel, host-specific factors and transmission pathways related to person-to-person contagion, animal contact, environmental exposures, and food vehicles. The meta-analytical models were fitted separately by population type. For some food classes, the effects of food preparation (e.g., eating raw, undercooked) and setting (i.e., eating food prepared outside the home) on the pooled OR were assessed by calculating the ratio of the mean OR when food is mishandled to the base OR.

The statistical analysis was designed to assess the effect of the geographical region, the study period and the analysis type (univariate/ multivariate) on the final result. The objective of the region-specific meta-analysis was to inform the decision on whether the geographical regions were to be maintained for the subsequent pooling of ORs. A geographical region (Asia, North America, South America, Africa, Europe, Oceania) was removed from a particular meta-analysis partition only if its pooled ORs were different from those associated with the other regions, or if less than 3 ORs represented the region (GonzalesBarron et al., 2019).

All meta-analytical models were essentially weighted random-effects linear regression models. Once a meta-analysis model was fitted, influential diagnostics statistics were applied to remove any influential observation originating from studies marked as having a potential for bias. Publication bias was assessed by funnel plots and a statistical test investigating the effect of the study sample size on the ORs (Tables 2, 3

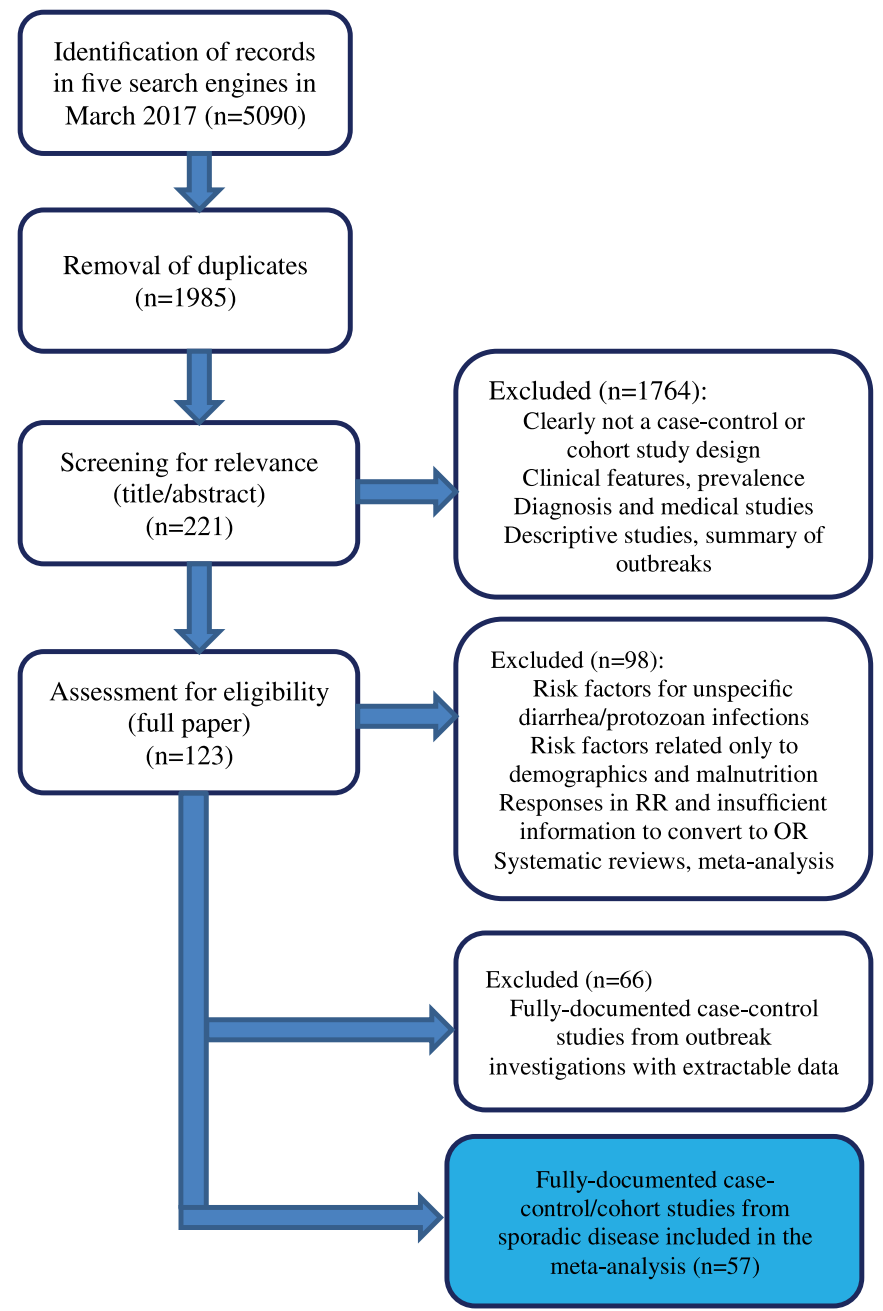

Fig. 1. Flowchart of literature search for case-control or cohort studies of human cryptosporidiosis. 
and 4) (Gonzales-Barron et al., 2019). Heterogeneity between studies was assessed by different indicators such as the between-study variability $\left(\tau^{2}\right)$, the QE test investigating residual heterogeneity, the variance of residuals and the intra-class correlation $\mathrm{I}^{2}$ (Gonzales-Barron et al., 2019). Publication bias and remaining heterogeneity were not further corrected for, but were taken into account for the interpretation of the results.

All analyses were carried out in the R software (R Development Core
Team, 2008) implemented with the metafor package (Viechtbauer, 2010).

The meta-analyzed risk factors are presented in summary tables only when significant. Pooled ORs were considered significant when the lower bound of the $95 \%$ confidence interval (CI) was equal or greater than 1.0, except for breastfeeding where the upper bound of the confidence interval had to be below 1 for it to be deemed as significant (protective effect).

Table 1

Characteristics of primary studies investigating risk factors for acquiring sporadic cryptosporidiosis included in the meta-analysis.

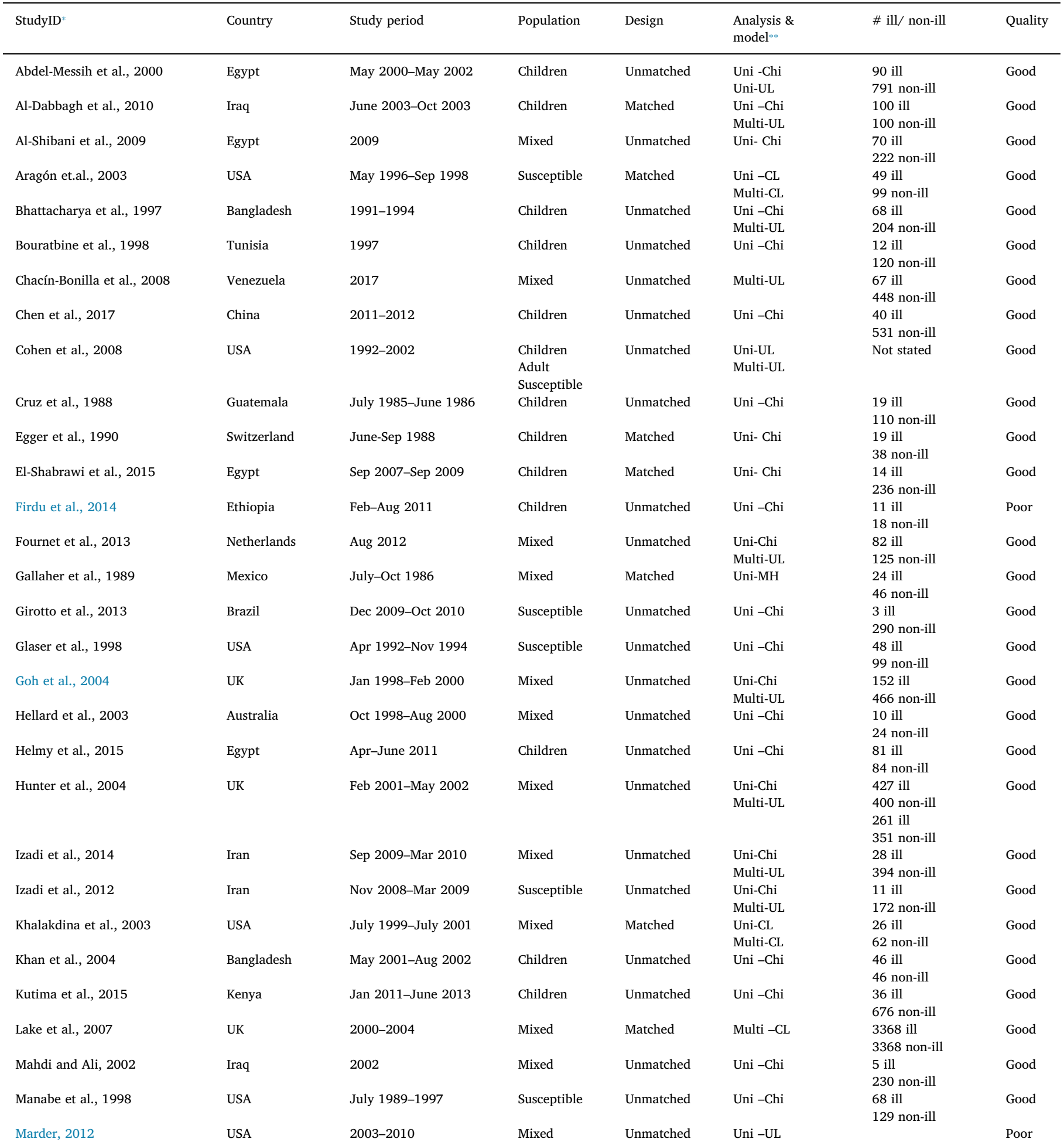


Table 1 (continued)

\begin{tabular}{|c|c|c|c|c|c|c|c|}
\hline StudyID* & Country & Study period & Population & Design & $\begin{array}{l}\text { Analysis \& } \\
\text { model }^{* *}\end{array}$ & \# ill/ non-ill & Quality \\
\hline & & & & & & $\begin{array}{l}6534 \text { ill } \\
30,890 \text { non-ill }\end{array}$ & \\
\hline Mbae et al., 2013 & Kenya & Jan 2010-Dec 2011 & Children & Unmatched & $\begin{array}{l}\text { Uni-Chi } \\
\text { Multi-UL }\end{array}$ & $\begin{array}{l}187 \text { ill } \\
1925 \text { non-ill }\end{array}$ & Good \\
\hline Mitra et al., 2016 & India & 2016 & Mixed & Unmatched & Uni -Chi & $\begin{array}{l}59 \text { ill } \\
233 \text { non-ill }\end{array}$ & Good \\
\hline Mølbak et al., 1994 & Guinea-Bissau & 1992 & Children & Matched & Multi-CL & $\begin{array}{l}125 \text { ill } \\
125 \text { non-ill }\end{array}$ & Good \\
\hline Mooji et al., 2015 & Netherlands & 2013-2015 & Mixed & Unmatched & $\begin{array}{l}\text { Uni-UL } \\
\text { Multi-UL }\end{array}$ & $\begin{array}{l}312 \text { ill } \\
587 \text { non-ill }\end{array}$ & Good \\
\hline Moore et al., 2016 & Cambodia & Apr-June 2012 & Children & Unmatched & $\begin{array}{l}\text { Uni-Chi } \\
\text { Multi-UL }\end{array}$ & $\begin{array}{l}38 \text { ill } \\
460 \text { non-ill }\end{array}$ & Good \\
\hline Morse et al., 2008 & Malawi & Jan 2001-Dec 2002 & Children & Unmatched & $\begin{array}{l}\text { Uni-Chi } \\
\text { Multi-UL }\end{array}$ & $\begin{array}{l}24 \text { ill } \\
72 \text { non-ill }\end{array}$ & Good \\
\hline Nassar et al., 2017 & Nigeria & July-Dec 2014 & Children & Unmatched & Uni-Chi & $\begin{array}{l}88 \text { ill } \\
100 \text { non-ill }\end{array}$ & Good \\
\hline Nchito et al., 1998 & Zambia & Nov 1995-Mar 1996 & Children & Unmatched & $\begin{array}{l}\text { Uni-Chi } \\
\text { Uni-MH }\end{array}$ & $\begin{array}{l}37 \text { ill } \\
179 \text { non-ill }\end{array}$ & Good \\
\hline $\mathrm{Ng}$ et al., 2012 & Australia & July-Aug 2010 & Mixed & Unmatched & Uni-Chi & $\begin{array}{l}15 \text { ill } \\
48 \text { non-ill }\end{array}$ & Good \\
\hline Nimri and Hijazi, 1994 & Jordan & July 1992-Sep 1993 & Children & Matched & Uni-Chi & $\begin{array}{l}18 \text { ill } \\
18 \text { non-ill }\end{array}$ & Good \\
\hline Osman et al., 2016 & Lebanon & Jan 2013 & Children & Unmatched & Uni-UL & $\begin{array}{l}26 \text { ill } \\
223 \text { non-ill }\end{array}$ & Good \\
\hline Pereira et al., 2002 & Brazil & Aug 1998-May 1999 & Children & Unmatched & Uni-UL & $\begin{array}{l}64 \text { ill } \\
380 \text { non-ill }\end{array}$ & Good \\
\hline Pintar et al., 2009 & Canada & Apr 2005-Dec 2007 & Mixed & Unmatched & $\begin{array}{l}\text { Uni-Chi } \\
\text { Multi-UL }\end{array}$ & $\begin{array}{l}36 \text { ill } \\
801 \text { non-ill }\end{array}$ & Poor \\
\hline Ravel et al., 2013 & Canada & June 2005-May 2009 & Mixed & Unmatched & Uni-Chi & $\begin{array}{l}51 \text { ill } \\
54 \text { non-ill }\end{array}$ & Poor \\
\hline Redlinger et al., 2002 & Mexico & Aug 1999-Mar 2000 & Mixed & Unmatched & Uni-Chi & $\begin{array}{l}298 \text { ill } \\
345 \text { non-ill }\end{array}$ & Poor \\
\hline Robertson et al., 2002 & Australia & June 1998-May 2001 & $\begin{array}{l}\text { Children } \\
\text { Mixed }\end{array}$ & Matched & $\begin{array}{l}\text { Uni-CL } \\
\text { Uni-CL } \\
\text { Multi-CL }\end{array}$ & $\begin{array}{l}64 \text { ill } \\
262 \text { non-ill } \\
201 \text { ill } \\
795 \text { non-ill }\end{array}$ & Good \\
\hline Roy et al., 2004 & USA & 1999-2001 & Mixed & Matched & $\begin{array}{l}\text { Uni-MH } \\
\text { Multi-CL }\end{array}$ & $\begin{array}{l}267 \text { ill } \\
464 \text { non-ill } \\
233 \text { ill } \\
467 \text { non-ill }\end{array}$ & Good \\
\hline Sarkar et al., 2014 & India & 2008-2013 & Children & Unmatched & $\begin{array}{l}\text { Uni-UL } \\
\text { Multi-UL }\end{array}$ & $\begin{array}{l}411 \text { ill } \\
180 \text { non-ill } \\
113 \text { ill } \\
51 \text { non-ill }\end{array}$ & Good \\
\hline Solorzano-Santos et al., 2000 & Mexico & 2000 & Children & Unmatched & $\begin{array}{l}\text { Uni-Chi } \\
\text { Multi-UL }\end{array}$ & $\begin{array}{l}10 \text { ill } \\
122 \text { non-ill }\end{array}$ & Good \\
\hline Sorvillo et al., 1994 & USA & 1983-1990 & Susceptible & Unmatched & Uni-MH & $\begin{array}{l}125 \text { ill } \\
2354 \text { non-ill }\end{array}$ & Good \\
\hline Srisuphanunt et al., 2008 & Thailand & 2007 & Susceptible & Unmatched & Uni-Chi & $\begin{array}{l}23 \text { ill } \\
120 \text { non-ill }\end{array}$ & Good \\
\hline Tellevik et al., 2015 & Tanzania & Aug 2010-July 2011 & Children & Unmatched & $\begin{array}{l}\text { Uni-Chi } \\
\text { Multi-UL }\end{array}$ & $\begin{array}{l}23 \text { ill } \\
397 \text { non-ill }\end{array}$ & Good \\
\hline Tumwine et al., 2003 & Uganda & Nov 1999-Jan 2001 & Susceptible & Matched & Uni-Chi & $\begin{array}{l}488 \text { ill } \\
1291 \text { non-ill }\end{array}$ & Good \\
\hline Valderrama et al., 2009 & USA & Aug-Sep 2007 & Mixed & Matched & $\begin{array}{l}\text { Uni-CL } \\
\text { Multi-CL }\end{array}$ & $\begin{array}{l}47 \text { ill } \\
92 \text { non-ill } \\
45 \text { ill } \\
89 \text { non-ill }\end{array}$ & Good \\
\hline Velasco et al., 2011 & Colombia & Feb-Apr 2009 & Susceptible & Unmatched & $\begin{array}{l}\text { Uni-Chi } \\
\text { Multi-UL }\end{array}$ & $\begin{array}{l}38 \text { ill } \\
93 \text { non-ill }\end{array}$ & Good \\
\hline Wilson et al., 2008 & NewZealand & 2006 & Mixed & Unmatched & Uni-Chi & $\begin{array}{l}534 \text { ill } \\
5395 \text { non-ill }\end{array}$ & Poor \\
\hline Yang et al., 2017 & China & Oct-Nov 2014 & Mixed & Unmatched & $\begin{array}{l}\text { Uni-Chi } \\
\text { Multi-UL }\end{array}$ & $\begin{array}{l}73 \text { ill } \\
543 \text { non-ill } \\
73 \text { ill } \\
542 \text { non-ill }\end{array}$ & Good \\
\hline
\end{tabular}

* References are listed in Appendix 1 .

** Uni: univariate analysis; Multi: multivariate analysis; Chi: chi-square test; MH: Mantel \& Haenzel method; UL: unconditional logistic regression; CL: conditional logistic regression. 


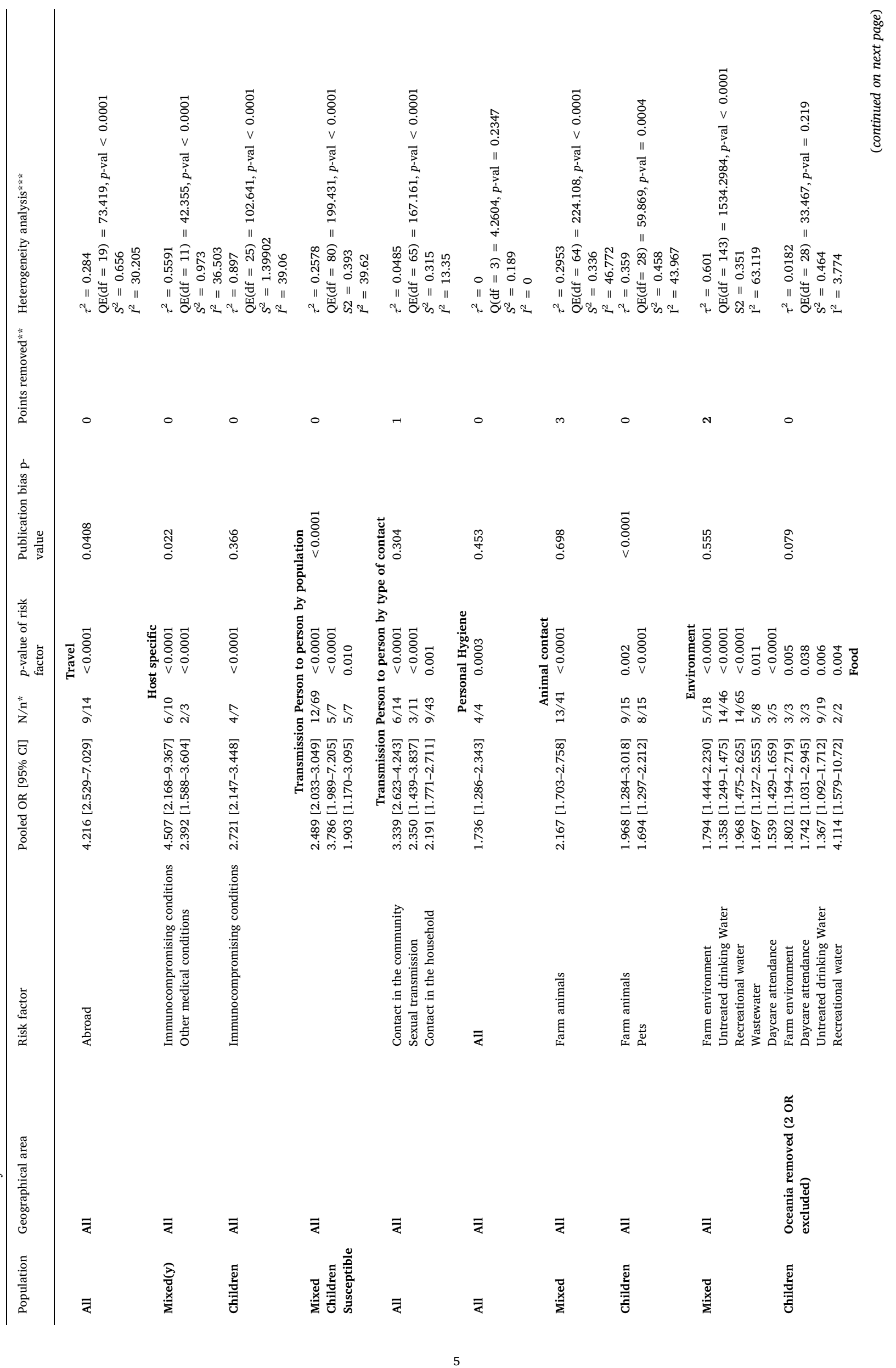




\section{Results}

\subsection{Descriptive statistics}

From 1985 identified references, the quality assessment stage was passed by 57 primary studies - cohort and case-control studies - focusing on sporadic cryptosporidiosis (Fig. 1). These published studies were conducted between 1983 and 2016. Table 1 and Appendix 1 compile the list of the primary studies along with their main features. The eligible studies jointly provided 568 odds-ratios categorized for meta-analysis. Meta-analytical data were obtained from primary studies conducted in 31 countries, although studies from only 5 countries generated $\sim 70 \%$ of the ORs retrieved. These were: USA ( 9 studies -136 ORs), UK ( 3 studies - 79 ORs), Australia (3 studies - 66 ORs), the Netherlands (2 studies - 66 ORs) and Canada ( 2 studies - 47 ORs).

Primary studies investigated risk factors in different types of population, namely children (27 studies), mixed population (24 studies) and susceptible population, which included immunocompromised individuals ( 8 studies) and elderly population (1 study). Separate metaanalyses were then adjusted on the mixed population (382 ORs), children (117 ORs) and susceptible (69 ORs). Most studies investigated illness caused by any Cryptosporidium species (49) or by C. parvum without distinction between $C$. parvum and $C$. hominis. Few studies investigated cases caused by $C$. parvum (3) or $C$. hominis (1). In all studies, the symptomatic cases of cryptosporidiosis were laboratory-confirmed.

With regards to the risk factor classes, sporadic illness investigations focused more on multiple pathways of exposure: environment (222 ORs), contact with animals (114 ORs), food ( $80 \mathrm{ORs),} \mathrm{person} \mathrm{to} \mathrm{person}$ (78 ORs). Host-specific factors (47 ORs), personal hygiene (4 ORs) and travel (23 ORs) were also investigated.

During methodological quality assessment, potential for selection bias status was assigned to six case-control studies since, in those, the controls were not healthy individuals but people affected by another enteric disease such as giardiasis (Firdu et al., 2014; Redlinger et al., 2002), salmonellosis (Marder, 2012), amoebiasis (Ravel et al., 2013), campylobacteriosis (Wilson et al., 2008), and one of nine other enteric infections (Pintar et al., 2009). As it is not clear whether these controls shared routes of exposure with the case patients, the ORs extracted from the aforementioned studies were marked as having potential for selection bias. These case-control studies provided 84 potentially-biased ORs whose influence on the meta-analyzed OR estimates was appraised by means of the Cook's distance.

Only 13 case-control studies employed a matched experimental design (Table 1). Bringing together the matched and unmatched designs, 379 ORs ( $67 \%$ of the data) were not adjusted by any confounder (crude ORs) (e.g. age, sex, other risk factors), while 189 ORs (33\%) were adjusted using either Mantel-Haenzel or logistic regressions.

\subsection{Meta-analysis}

The meta-analysed significant risk factors are presented in summary tables (Table 2 and 3). Non-significant results on the main risk factors are presented in Appendix 2. More detailed descriptive results, in particular, funnel plots, forest plots, and OR of non-significant results, are in a complete report available upon request.

\subsubsection{Meta-analysis for travel}

According to this meta-analysis, foreign travel is an important risk factor for acquiring cryptosporidiosis. For residents of USA, UK, Switzerland, Netherlands, Australia and New Zealand, traveling abroad increased their odds of acquiring cryptosporidiosis (pooled $\mathrm{OR}=4.216$; 95\% CI [2.529-7.029]) (Table 2; Fig. 2).

\subsubsection{Meta-analysis for host-specific risk factors}

The meta-analysis on host-specific factors showed that immunocompromising conditions were associated with cryptosporidiosis 
Table 3

Results of the meta-analysis on disaggregated risk factors.

\begin{tabular}{|c|c|c|c|c|c|c|c|c|c|}
\hline Risk Factor & Population & Geographical area & $\begin{array}{l}\text { Risk factor } \\
\text { precise }\end{array}$ & $\begin{array}{l}\text { Pooled OR }[95 \% \\
\mathrm{CI}]\end{array}$ & $\mathrm{N} / \mathrm{n}^{*}$ & $\begin{array}{l}p \text {-value of } \\
\text { risk factor }\end{array}$ & $\begin{array}{l}\text { Publication bias } \\
\text { p-value }\end{array}$ & $\begin{array}{l}\text { Points } \\
\text { removed** }\end{array}$ & Heterogeneity analysis*** \\
\hline Meat & $\begin{array}{l}\text { Mixed \& } \\
\text { Susceptible }\end{array}$ & All & Others**** & $\begin{array}{l}1.991 \\
{[1.288-3.080]}\end{array}$ & $3 / 8$ & 0.002 & 0.890 & 0 & $\begin{array}{l}\tau^{2}=0 \\
\mathrm{QE}(\mathrm{df}=8)=4.5068 \\
p \text {-val }=0.809 \\
\mathrm{~S}^{2}=0.243 \\
\mathrm{I}^{2}=0\end{array}$ \\
\hline Dairy & $\begin{array}{l}\text { Mixed \& } \\
\text { Children }\end{array}$ & All & Milk & $\begin{array}{l}1.509[1.071- \\
-2.125]\end{array}$ & $6 / 8$ & 0.019 & 0.647 & 0 & $\begin{array}{l}\tau^{2}=0 \\
\mathrm{QE}(\mathrm{df}=10)=8.5624 \\
p \text {-val }=0.574 \\
\mathrm{~S}^{2}=0.0 .205 \\
\mathrm{I}^{2}=0\end{array}$ \\
\hline Composite & $\begin{array}{l}\text { Mixed \& } \\
\text { Children }\end{array}$ & All & Dishes & $\begin{array}{l}1.717 \\
{[1.220-2.416]}\end{array}$ & $6 / 17$ & 0.002 & 0.015 & 0 & $\begin{array}{l}\tau^{2}=0.142 \\
\mathrm{QE}(\mathrm{df}=18)=126.1028 \\
p \text {-val }<0.0001 \\
\mathrm{~s} 2=0.330 \\
\mathrm{I}^{2}=30.085\end{array}$ \\
\hline BBQ & All & All & BBQ & $\begin{array}{l}2.005 \\
{[1.624-2.476]}\end{array}$ & $2 / 4$ & $<0.0001$ & 0.383 & 0 & $\begin{array}{l}\tau^{2}=0 \\
Q(\mathrm{df}=3)=26.214 \\
p \text {-val }<0.0001 \\
\mathrm{~S}^{2}=0.315 \\
\mathrm{I}^{2}=0\end{array}$ \\
\hline
\end{tabular}

*N/n Number of studies/number of OR;** points removed by sensitivity analysis, all results are given after removing data concerned; ***Between-study variability $\left(\tau^{2}\right)$, test for residual heterogeneity $(\mathrm{QE})$, variance of residuals $\left(\mathrm{s}^{2}\right)$, intra-class correlation $\left(\mathrm{I}^{2}\right)$; **** Meats of non-specified origin.

for the mixed, children with pooled ORs ranging from 2.721 to 4.507. For the mixed and children population, immunocompromising conditions included HIV infection, other immune system illnesses, the use of immunosuppressive medication, etc. Other medical conditions, including chronic disease and HBV infection, were also found to be associated with cryptosporidiosis in the mixed population (pooled $\mathrm{OR}=2.392 ; 95 \%$ CI $[1.588-3.604])$.

\subsubsection{Meta-analysis for person to person transmission factors}

Person-to-person transmission was a significant risk factor of acquiring cryptosporidiosis for all the populations (pooled OR ranging from 1.903 to 3.786; Table 2; Fig. 3). The same data set related to person-to-person transmission was stratified in three classes according to the type or the location of the contact. Significant associations were found for contact in household (pooled OR $=2.191 ; 95 \% \mathrm{CI}$ [1.771-2.711]), contact in the community (pooled OR $=3.339 ; 95 \% \mathrm{CI}$ [2.623-4.243]) and sexual transmission (pooled OR $=2.350 ; 95 \% \mathrm{CI}$ [1.439-3.837]).

Poor personal hygiene (e.g. "no handwashing after toilet", " poor hygiene habits") could be a risk factor for cryptosporidiosis (pooled $\mathrm{OR}=1.736 ; 95 \%$ CI $[1.286-2.343])$.

\subsubsection{Meta-analysis for animal contact}

Contact with animals was associated with an increased risk of cryptosporidiosis. Significant associations were found for farm animals in the mixed population (pooled OR $=2.167 ; 95 \%$ CI $[1.703-2.758]$; Fig. 4) and children (pooled OR $=1.968$; 95\% CI [1.284-3.018]) and pets in children (pooled OR $=1.694 ; 95 \%$ CI [1.297-2.212]).

\subsubsection{Meta-analysis for environmental factors}

In both the mixed and children populations, the environmental pathways under study were significantly associated with cryptosporidiosis: recreational water (pooled OR $=1.968$; 95\% CI [1.475-2.625] for the mixed population (Fig. 5); pooled OR $=4.114 ; 95 \% \mathrm{CI}$ [1.579-10.715] for children); farm environment (pooled OR = 1.794; 95\% CI [1.444-2.230] for the mixed population and pooled $\mathrm{OR}=1.802$; 95\% CI [1.194-2.719] for children), attendance to daycare (pooled OR $=1.539 ; 95 \%$ CI [1.429-1.659] for the mixed population and pooled $\mathrm{OR}=1.742$; 95\% CI [1.031-2.945] for children), untreated drinking water (pooled OR $=1.358$; 95\% CI [1.249-1.475] for the mixed population and pooled $\mathrm{OR}=1.367 ; 95 \% \mathrm{CI}$
[1.092-1.712] for children) and wastewater (only in the mixed population: pooled OR $=1.697 ; 95 \%$ CI $[1.127-2.555]$ ). Data from Oceania ( 2 ORs) were removed from the children population. This exclusion only affects the significance of the OR related to attendance to daycare.

\subsubsection{Meta-analysis for food consumption}

The meta-analysis on food consumption pathways revealed significant associations with meat (pooled OR $=1.934 ; 95 \% \mathrm{CI}$ [1.236-3.024]; Fig. 6) and dairy (pooled OR $=1.533$; 95\% CI [1.009-2.329]; Fig. 7) for the mixed population, and composite foods (pooled OR $=1.532 ;$ 95\% CI [1.072-2.189]) for children. Within the food vehicles, associations with cryptosporidiosis were observed for: barbecue foods (pooled OR $=2.005 ; 95 \%$ CI [1.624-2.476]), meat of non-specified origin ("Others"; pooled OR $=1.991 ; 95 \% \mathrm{CI}$ [1.288-3.080]), dishes prepared outside the home (pooled OR = 1.717; 95\% CI [1.220-2.416]) and milk (comprising essentially raw milk in this category) (pooled OR $=1.509 ; 95 \%$ CI [1.071-2.125]). If we restrict the analysis to raw milk, combining ORs in population mixed and children with $7 \mathrm{OR}$, the raw milk is still significant at a pooled OR of 1.670 (95\% CI [1.035-2.695]).

Food categories that on meta-analysis had a non-significant association with cryptosporidiosis were produce (comprising raw or fresh vegetables (10 ORs) and unwashed fruits (1 OR) and beverage. The only food data partitions comprising sufficient data that could support the assessment of the effect of handling were those of produce and dairy (Table 4). It was found that people who ate unwashed fruits and vegetables, had their odds of infection significantly increased by a factor of 1.572. Hence, the practice of not washing vegetables before consumption represents on its own a risk factor for cryptosporidiosis.

For most of the meta-analytical models reported in Tables 2-4, the statistical tests indicated the absence of potential significant publication bias at 5\% significance. Exception is observed for partitions related to travel, host-specific in the mixed population, person-to-person transmission, animal contact in children, and composite foods. However, for these five partitions, the spread of data points within the funnel plot does not hint any evidence of a strong publication bias problem (Fig. 8). Moreover, the intra-class correlation $I^{2}$ indicates low $(<25 \%)$ to moderate $(<50 \%)$ heterogeneity (Tables $2-4)$. Remaining between-study heterogeneity (significant $p$-values below 0.05 for $\mathrm{Q}$ or $\mathrm{QE}$ ) was observed for most of the data partitions. 


\begin{tabular}{|c|c|c|c|c|c|}
\hline Study & Country & Label & Odds Ratio & {$[95 \% \mathrm{Cl}]$} & \\
\hline Egger_ADC_1990 & Switzerland & Travelled in Mediterranean country & 6.43 & {$[1.11-37.08]$} & $\longrightarrow$ \\
\hline Fournet_Eurosurveillance_2013 & Netherlands & Travel abroad in Europe & 2 & {$[1.08-3.7]$} & - \\
\hline Glaser_AIDS_1998 & USA & Travel outside USA & 1.61 & [0.73-3.55] & - \\
\hline Hunter_EID_2004* & UK & Travel outside UK & 5.65 & {$[2.86-11.16]$} & - \\
\hline Hunter_EID_2004* & UK & Travel outside UK & 6.84 & {$[2.62-17.85]$} & $\longrightarrow$ \\
\hline Hunter_EID_2004 & UK & Travel outside UK & 4.74 & {$[2.89-7.85]$} & - \\
\hline Khalakdina_BMCPH_2003 & USA & Travel to another country & 25.7 & [3.28-201] & $\rightarrow$ \\
\hline Khalakdina_BMCPH_2003* & USA & Travel to another country & 20.9 & [1.55-279] & $\rightarrow$ \\
\hline Robertson_Epilnf_2002 & Australia & Travel overseas & 8.6 & {$[4.8-15.6]$} & - \\
\hline Robertson_Epilnf_2002 & Australia & Travel overseas & 5.6 & [2.1-14.6] & $-\square$ \\
\hline Roy_JCM_2004* & USA & International travel & 7.8 & [3.3-18.4] & $\longrightarrow$ \\
\hline Roy_JCM_2004* & USA & International travel & 7.7 & [2.7-22] & - \\
\hline Valderrama_Epilnf_2009 & USA & International travel & 2 & [0.3-14.2] & - 들 \\
\hline Wilson_EPI_2008 & NewZealand & Overseas travel & 1.4 & {$[1-1.9]$} & - \\
\hline Random Effect Meta-Analysis & All & & 4.22 & [2.53-7.03] & $\sim$ \\
\hline
\end{tabular}

Fig. 2. Forest plot of the association of cryptosporidiosis with travel abroad in all populations $(n=14)$ (* adjusted OR)

\begin{tabular}{|c|c|c|c|c|c|}
\hline Study & Country & Label & Odds Ratio & {$[95 \% \mathrm{Cl}]$} & \\
\hline Chen_JBP_2017 & China & Household member with diarrhoea & 2.66 & {$[1.04-6.8]$} & \\
\hline Egger_ADC_1990 & Switzerland & Contact with person with diarrhoea & 41.11 & [4.64-364.02] & $>$ \\
\hline Egger_ADC_1990 & Switzerland & Visited kindergarten & 4.8 & {$[0.79-29.07]$} & $\Rightarrow$ \\
\hline Morse_InProceeding_2008 & Malawi & Household member with diarrhoea & 8.8 & {$[1.8-53.4]$} & $\Rightarrow$ \\
\hline Osman_PLOS_2016 & Lebanon & Household member with gastroenteritis & 1.7 & {$[0.8-4]$} & \\
\hline Solorzano-Santos_RIC_2000 & Mexico & Diarrhoea in family & 5.82 & [0.86-39.18] & \\
\hline Solorzano-Santos_RIC_2000* & Mexico & Diarrhoea in family & 4.15 & {$[0.47-36.91]$} & \\
\hline Random Effect Meta-Analysis & All & & 3.79 & [1.99-7.21] & \\
\hline
\end{tabular}

Fig. 3. Forest plot of the association of cryptosporidiosis with person-to-person transmission in children $(n=7)(*$ adjusted OR) 


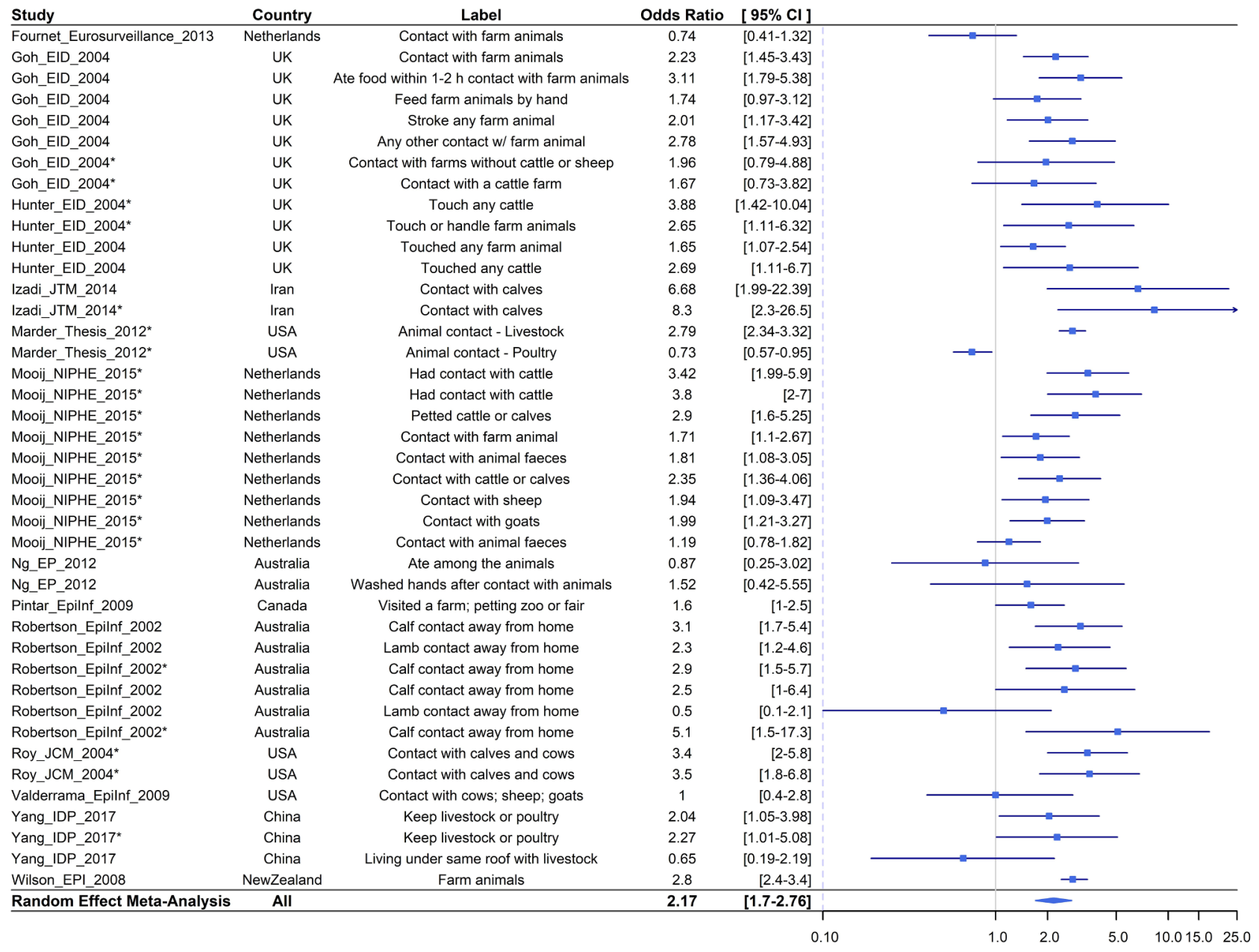

Fig. 4. Forest plot of the association of cryptosporidiosis with contact with farm animals in the mixed population $(n=41)\left({ }^{*}\right.$ adjusted OR)

\section{Discussion}

This meta-analysis identified foreign travel (pooled OR $=4216$ ), immunocompromising conditions (pooled OR ranging from 2.721 to 4.507), person-to-person transmission (pooled OR ranging from 1.903 to 3.786), environmental pathways (pooled OR ranging from 1.358 to 1.968 in the mixed population), animal contact (pooled OR ranging from 1.694 to 2.167), and food consumption (pooled OR ranging from 1.533 to 1.934) as risk factors of cryptosporidiosis. For person-toperson, environmental and animal contact pathways, the same risk factors were identified in the mixed population and children. Food exposures were less investigated in children compared to the mixed population. Fewer studies investigated the susceptible population (immunocompromised individuals and elderly) and the pooled OR related to animal, environmental and food exposures were non-significant.

Overall, these meta-analytical results are in line with the epidemiology of Cryptosporidium (EFSA BIOHAZ Panel, 2018). Few studies investigated cases caused specifically by $C$. parvum (11) or C. hominis (1). Although the epidemiology of both $C$. parvum and $C$. hominis could involve indirect transmission routes (water, foods), there are some specificities. C. hominis, which infects mainly humans, is transmitted through the fecal-oral pathway and, hence, person-to-person transmission plays a major role in the transmission. On the other hand, the main reservoir of $C$. parvum is ruminants, and, as such, zoonotic transmission could occur through animal contact.

Foreign travel is a known risk factor of cryptosporidiosis (Hagmann et al., 2014). However, due to the lack of information on the countries of travel, it was not possible to identify regions at particular risk (Fig. 2).

The host susceptibility risk factors (in particular immunosuppression linked to AIDS) have been established in previous studies (Hunter and Nichols, 2002).

Person-to-person transmission is a known risk factor of cryptosporidiosis. In this meta-analysis, higher pooled OR were obtained for children compared to adults (Fig. 3). This might be related to higher exposure due to the lack of hygiene, greater susceptibility, and less immunity. Regarding the person-to-person pathways, contact with an ill person at home (contact in the household), contact in institutions (child /daycare, schools, etc.) and contact during sexual activity were significantly associated with cryptosporidiosis. The lack of personal hygiene (lack of handwashing), identified as a risk factor, can lead to person-to-person transmission.

The meta-analysis confirms the major role of water in the transmission of cryptosporidiosis. Exposure to recreational waters, wastewater (lack of sanitation) and the consumption of untreated drinking water significantly increase the risk of cryptosporidiosis. Many outbreaks of cryptosporidiosis have been associated with the consumption of drinking water (Dalle et al., 2003; Eisenberg et al., 2005; Moreira and Bondelind, 2017), and the ingestion of bathing water in swimming pools or leisure facilities (first cause of outbreak in the United States and the United Kingdom) (Gharpure et al., 2019; Ryan et al., 2017). Cryptosporidium is often present in aquatic environments from fecal sources and can be found in a large range of concentrations (1 to several hundred oocysts /L) (Nasser, 2015). Cryptosporidium oocysts can bypass common water treatments during occasional failure of the filtration (Lonigro et al., 2006), and are highly 


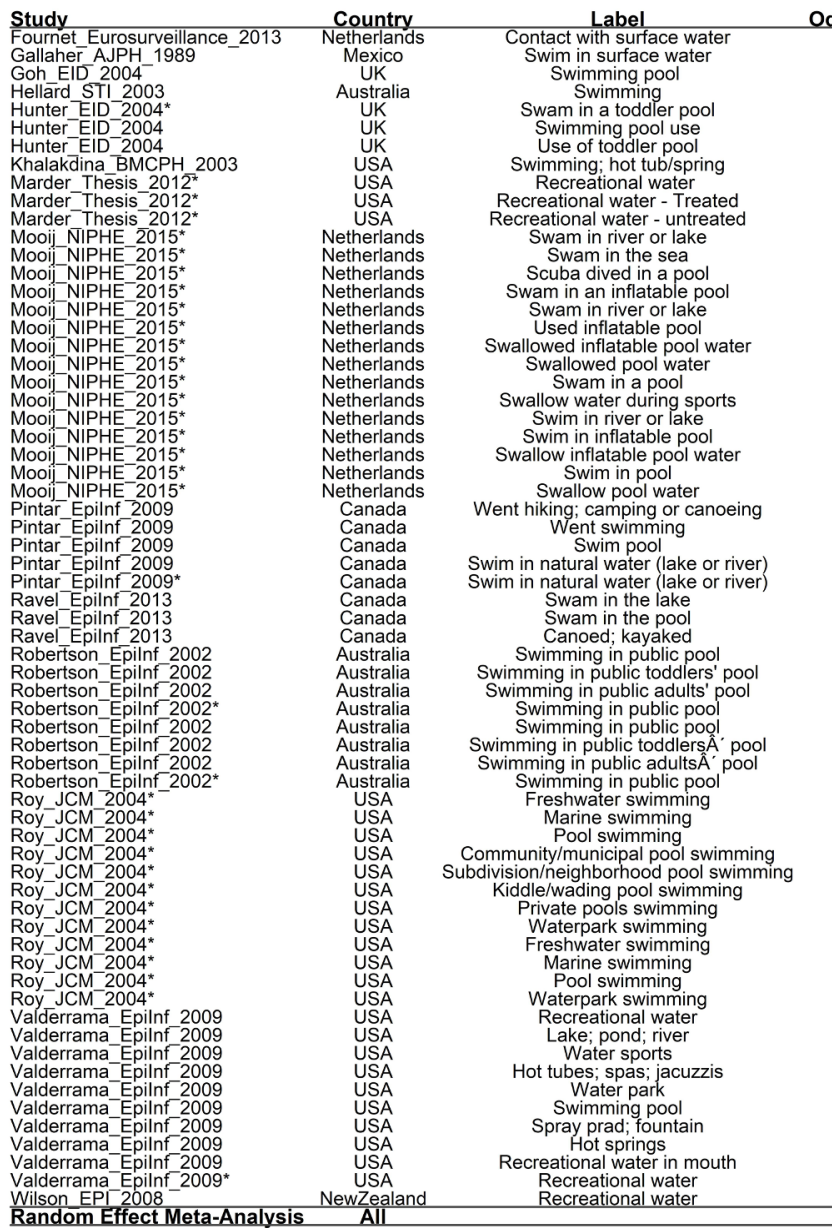

Random Effect Meta-Analysis

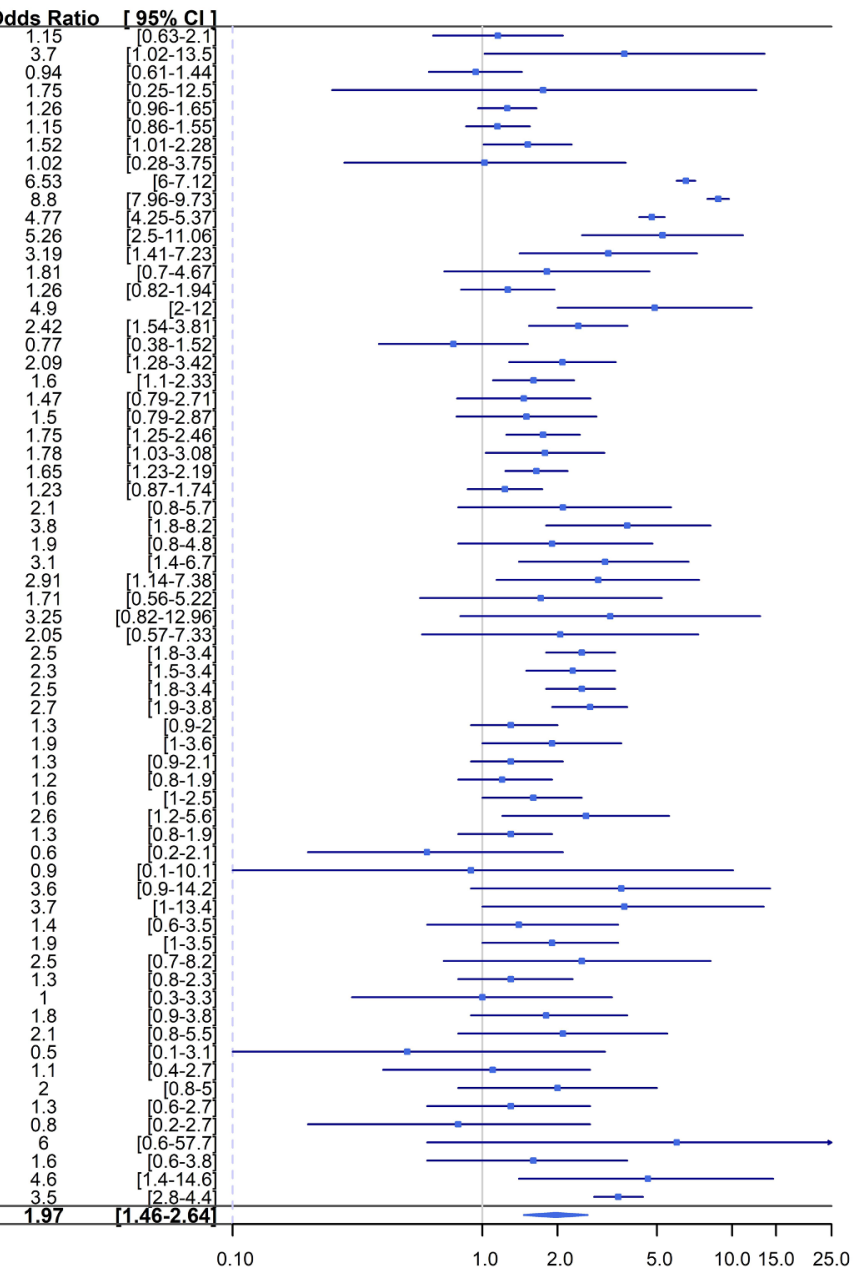

Fig. 5. Forest plot of the association of cryptosporidiosis with contact with recreational waters in the mixed population ( $(n=65)(*$ adjusted OR).

resistant to disinfection procedures like chlorination (Erickson and Ortega, 2006).

Contact with farm animals and farm attendance are identified as risk factors, which is supported by described outbreaks. In the US, contact with infected cattle is the second cause of cryptosporidiosis outbreaks, responsible for $15 \%$ outbreaks for the period 2009-2017 (Gharpure et al., 2019). Several outbreaks have also been reported in Europe (Lange et al., 2014; Utsi et al., 2016; Alsmark et al., 2018). Possession of a pet is only significant in children. The role of pets (dogs and cats) in the transmission of cryptosporidiosis is nevertheless not established in the literature (de Lucio et al., 2017; Lucio-Forster et al., 2010).

Among the food-related risk factors, meat was found as a risk factor, which was less expected. Only one outbreak linked to the consumption of raw meat has been reported (Yoshida et al., 2007). Within the meat category, meat of unspecified origin ("others") is found significant but beef is not a significant risk factor (with only 2 ORs from 2 publications). None of the ORs are significant in each study alone (3 studies from Canada and the United Kingdom), but this factor appears significant by the combination of ORs in the meta-analysis (8 ORs) (Fig. 6). This association could reflect fecal contamination of beef carcasses during the slaughter process, as observed with other enteric pathogens (e.g. Salmonella, or Shigatoxin-producing E. coli). Data on the contamination of meat by Cryptosporidium are however limited. The prevalence of Cryptosporidium spp. in feces and meat samples were investigated by Moriarty et al. (2005): Cryptosporidium spp. were isolated from fecal samples (7.3\%) but not from carcasses samples. To confirm the plausibility of this association, meat should be explored in specific surveys and investigations of outbreaks and sporadic cases of cryptosporidiosis.

The consumption of dishes prepared outside home and BBQ foods were also found significantly associated with Cryptosporidium. This can be linked to poor hygiene practices (e.g. contamination by an infected handler during the preparation of these products).

Unpasteurized milk and dairy products emerged as a risk factor in the meta-analysis. This result is consistent with published outbreaks (Harper et al., 2002; Loury et al., 2019; Rosenthal et al., 2015). C. parvum was listed among microbiological hazards potentially transmissible through milk and present in the EU milk-producing animal population (EFSA BIOHAZ Panel, 2015). However, identification and isolation methods of Cryptosporidium are not standardized in dairy products and these products are rarely found contaminated during outbreaks investigations (Loury et al., 2019).

Produce (washed and not washed in the same category) was not identified as a risk factor, but the consumption of poorly washed fruits and vegetables significantly increases ORs. Fresh produce is the main vehicle of foodborne cryptosporidiosis outbreaks (Aberg et al., 2015; England, 2017; Ethelberg et al., 2009; McKerr et al., 2015). Nevertheless, several case-control studies found that the consumption of vegetables is a protective factor against cryptosporidiosis (Goh et al., 2004; Nic Lochlainn et al., 2019; Roy et al., 2004). Roy et al. (2004) explained this effect by the acquisition of protective immunity following repeated exposure to low doses of oocysts on contaminated vegetables as observed in waterborne outbreaks (Hunter, 2000). Produce (vegetables) should be better studied by taking into account the type of vegetable (more exposed or not to irrigation of contaminated 


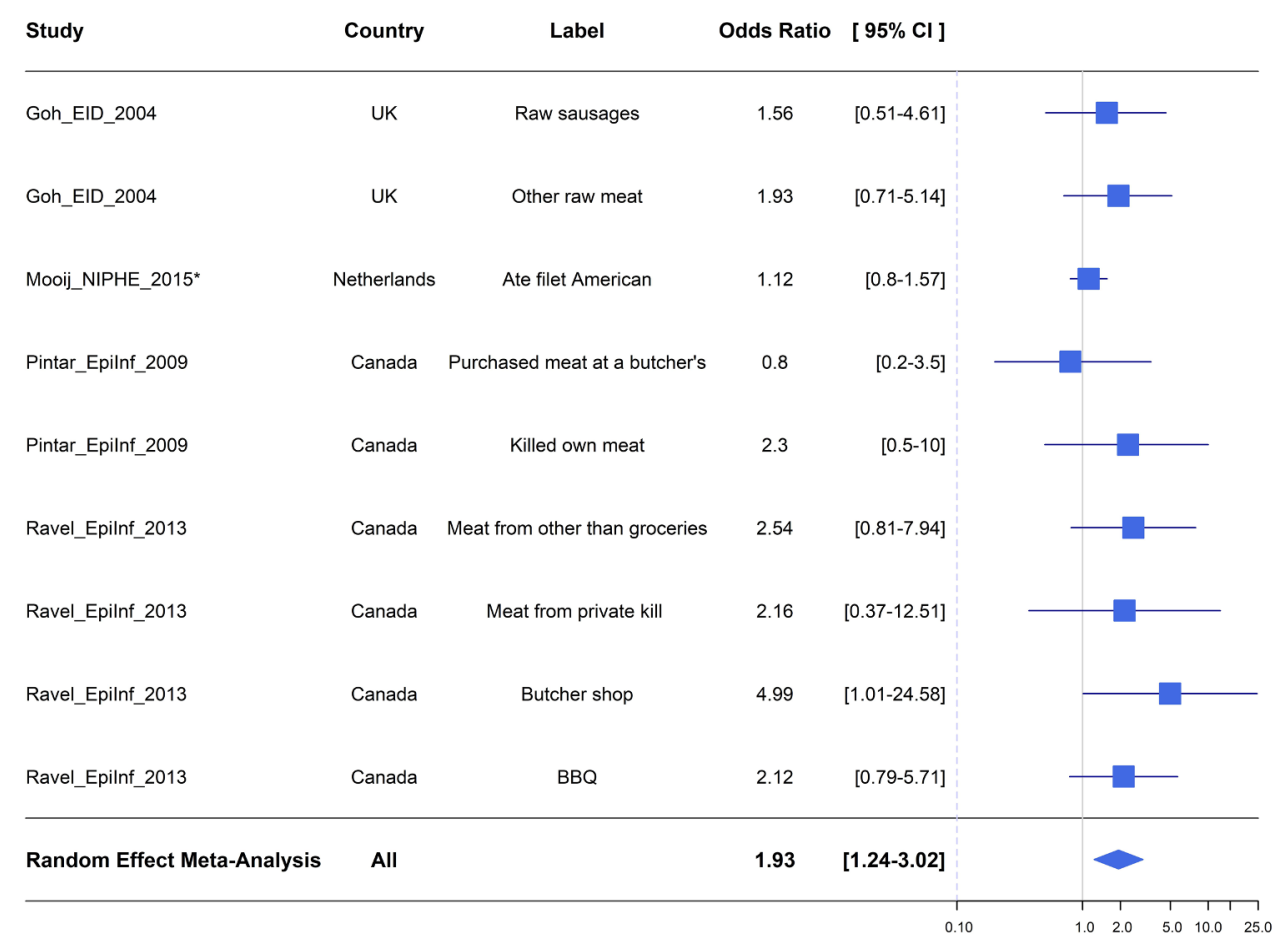

Fig. 6. Forest plot of the association of cryptosporidiosis with meat consumption in the mixed population ( $\mathrm{n}=9)(*$ adjusted OR).

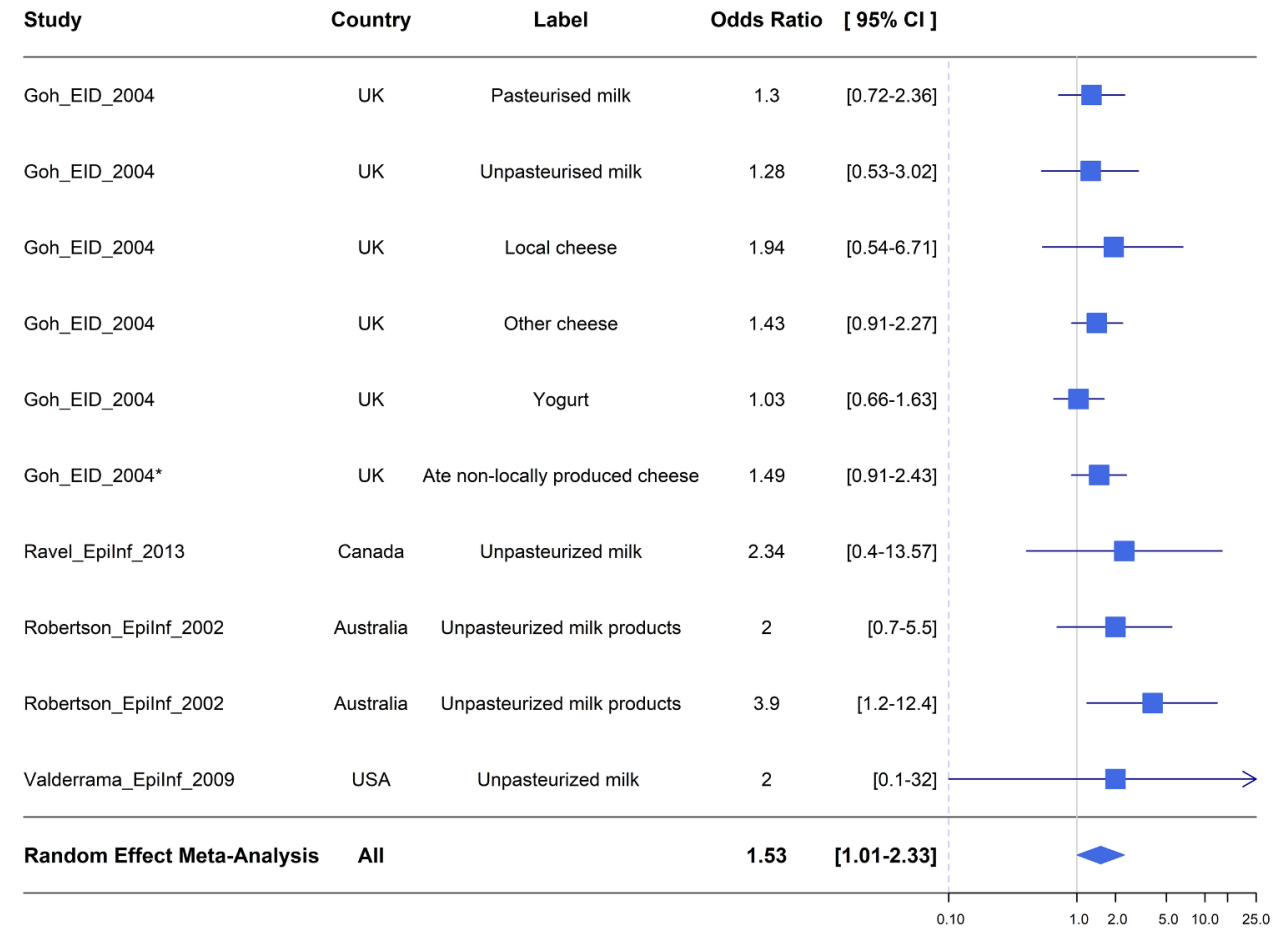

Fig. 7. Forest plot of the association of cryptosporidiosis with dairy consumption in the mixed population ( $\mathrm{n}=10)(*$ adjusted OR).

waters, such as lettuce) and the type of preparation (washed or not).

Beverages (including cider/bottled water/ice) were not identified as a risk factor in the meta-analysis. Cider was investigated in one study and was found non-significant (Roy et al., 2004). Apple cider/juice has been responsible for two outbreaks in the USA (Blackburn et al., 2006; Millard et al., 1994) and recently in Norway (Robertson et al., 2019). Recommendations have been made on grazing animals in orchards and washing fruits. Shellfish are considered as potential vehicles of
Cryptosporidium but were not investigated in the included studies. Although shellfish have been found contaminated with Cryptosporidium oocysts in several surveys (Giangaspero et al., 2014; GomezBautista et al., 2000; Gomez-Couso et al., 2006; Robertson and Gjerde, 2008), no outbreaks have been reported to date. The role of shellfish in Cryptosporidium infections should be investigated in future case-control studies.

Our results are comparable to the meta-analysis conducted by 


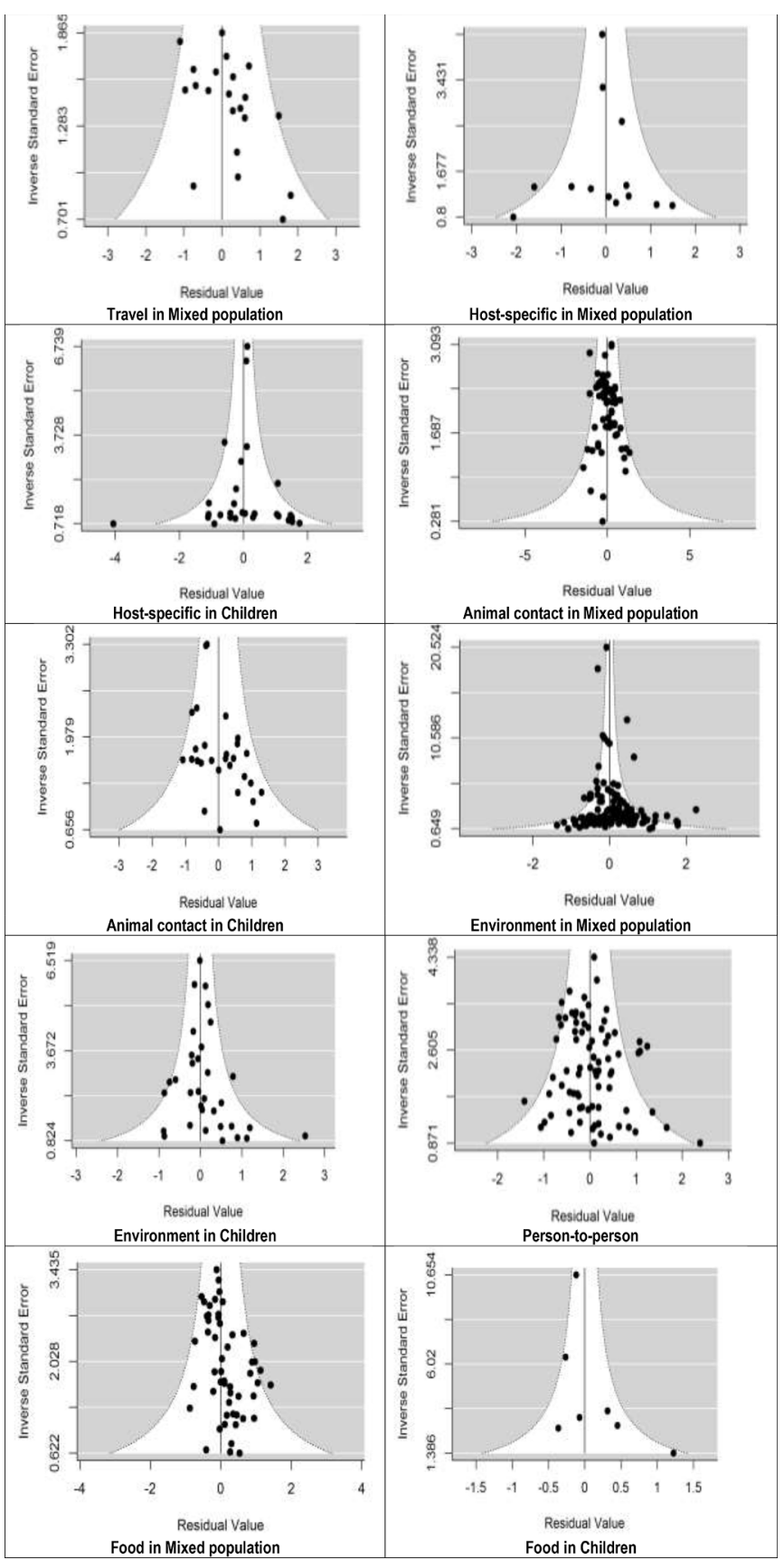

Fig. 8. Funnel plots of studies investigating categorized risk factors (travel, host-specific, environment, animal contact, person to person and food).

Bouzid et al. (2018) who reported diarrhea in the household, animal contact, lack of toilet facility and overcrowded conditions as risk factors for cryptosporidiosis in low and middle-income countries based on 11 studies. Food exposures were not investigated in the included studies and poor drinking water was not found significant. These differences may be related to the analysis strategy of Bouzid et al. (2018) as only studies reporting at least four relevant risk factors were included in their meta-analysis.

\section{Conclusion}

In summary, this meta-analysis confirmed known risk factors of cryptosporidiosis linked to anthroponotic and zoonotic pathways of transmission: contact with infected humans, waterborne transmission, contact with animals and food consumption. Except for meat, the 
identified vehicles are all consistent with described outbreaks.

Future case-control studies of sporadic infections should better explore the role of dairy, shellfish, meat, and vegetables, including washing/cooking and hygiene practices. These risk factors should also be included in questionnaires used for outbreak investigations. Moreover, the development of sensitive methods (based on molecular assays) for detection and isolation of Cryptosporidium oocysts in these different matrices is necessary to link cases to food items (Rousseau et al., 2018). Susceptible populations, such as children, elderly or immunosuppressed people could be better addressed, due to the severity of cases in those populations. The immunity should be taken into account to reduce misclassification in case-control studies (Hunter, 2000). It may be interesting to consider serology, in addition to criteria related to symptoms, and parasite excretion. In order to improve the detection of cases, biological diagnosis of persistent diarrhea should specify Cryptosporidium research (Loury et al., 2019).

Lastly, subtyping of human isolates can provide insights into the epidemiology of cryptosporidiosis, allowing the identification of risk factors specific to species or subtypes.

\section{CRediT authorship contribution statement}

Pauline Kooh: Methodology, Project administration, Writing original draft. Anne Thébault: Methodology, Formal analysis, Writing review \& editing. Vasco Cadavez: Methodology, Investigation, Formal analysis. Ursula Gonzales-Barron: Methodology, Investigation, Formal analysis, Writing - review \& editing. Isabelle Villena: Supervision, Writing - review \& editing.

\section{Declaration of Competing Interest}

The authors declare no conflict of interest.

\section{Acknowledgments}

The authors would like to thank ANSES staff and the members of the ANSES Working Group on Source Attribution of Foodborne Diseases: Moez Sanaa, Laurence Watier, Jean Christophe Augustin, Frédéric Carlin, Julie David, Philippe Fravalo, Laurent Guillier, Nathalie Jourdan-Da Silva, Alexandre Leclercq, Lapo Mughini-Gras, Nicole Pavio.

Ursula Gonzales-Barron and Vasco Cadavez are grateful to the Foundation for Food Science and Technology (FCT, Portugal) and FEDER under Programme PT2020 for financial support to CIMO (UID/ AGR/00690/2019).

\section{Supplementary materials}

Supplementary material associated with this article can be found, in the online version, at doi:10.1016/j.mran.2020.100116.

\section{References}

Aberg, R., Sjoman, M., Hemminki, K., Pirnes, A., Rasanen, S., Kalanti, A., Pohjanvirta, T., Caccio, S.M., Pihlajasaari, A., Toikkanen, S., Huusko, S., Rimhanen-Finne, R., 2015. Cryptosporidium parvum caused a large outbreak linked to frisee salad in Finland, 2012. Zoonoses Public Health 62, 618-624.

Alsmark, C., Nolskog, P., Angervall, A.L., Toepfer, M., Winiecka-Krusnell, J., Bouwmeester, J., Bjelkmar, P., Troell, K., Lahti, E., Beser, J., 2018. Two outbreaks of cryptosporidiosis associated with cattle spring pasture events. Vet. Parasitol. 14, $71-74$.

Blackburn, B.G., Mazurek, J.M., Hlavsa, M., Park, J., Tillapaw, M., Parrish, M., Salehi, E., Franks, W., Koch, E., Smith, F., Xiao, L., Arrowood, M., Hill, V., da Silva, A., Johnston, S., Jones, J.L., 2006. Cryptosporidiosis associated with ozonated apple cider. Emerg. Infect. Dis, 12, 684-686.

Bouzid, M., Kintz, E., Hunter, P.R., 2018. Risk factors for Cryptosporidium infection in low and middle income countries: a systematic review and meta-analysis. PLoS Negl. Trop. Dis. 12, e0006553.

Dalle, F., Roz, P., Dautin, G., Di-Palma, M., Kohli, E., Sire-Bidault, C., Fleischmann, M.G.,
Gallay, A., Carbonel, S., Bon, F., Tillier, C., Beaudeau, P., Bonnin, A., 2003. Molecular characterization of isolates of waterborne Cryptosporidium spp. collected during an Outbreak of gastroenteritis in South Burgundy. France J. Clin. Microbiol. 41, 2690-2693.

de Lucio, A., Bailo, B., Aguilera, M., Cardona, G.A., Fernandez-Crespo, J.C., Carmena, D., 2017. No molecular epidemiological evidence supporting household transmission of zoonotic Giardia duodenalis and Cryptosporidium spp. from pet dogs and cats in the province of Alava. Northern Spain. Acta Trop. 170, 48-56.

ECDC, 2019. Cryptosporidiosis. Annual Epidemiological Report For 2017, ECDC, ed. ECDC, Stockholm.

EFSA BIOHAZ Panel, 2018. Public health risks associated with food-borne parasites. EFSA Journal 16.

EFSA BIOHAZ Panel, 2015. Scientific Opinion on the public health risks related to the consumption of raw drinking milk. EFSA Journal 13, 3940.

Eisenberg, J.N., Lei, X., Hubbard, A.H., Brookhart, M.A., Colford Jr., J.M., 2005. The role of disease transmission and conferred immunity in outbreaks: analysis of the 1993 Cryptosporidium outbreak in Milwaukee. Wisconsin. Am. J. Epidemiol. 161, 62-72.

Erickson, M.C., Ortega, Y.R., 2006. Inactivation of protozoan parasites in food, water, and environmental systems. J. Food Prot. 69, 2786-2808.

Ethelberg, S., Lisby, M., Vestergaard, L.S., Enemark, H.L., Olsen, K.E., Stensvold, C.R., Nielsen, H.V., Porsbo, L.J., Plesner, A.M., Molbak, K., 2009. A foodborne outbreak of Cryptosporidium hominis infection. Epidemiol. Infect. 137, 348-356.

Firdu, T., Abunna, F., Girma, M., 2014. Intestinal protozoal parasites in diarrheal children and associated risk factors at Yirgalem hospital, Ethiopia: a case-control study. Int. Sch. Res. Notices 2014, 357126.

Gharpure, R., Perez, A., Miller, A.D., Wikswo, M.E., Silver, R., Hlavsa, M.C., 2019. Cryptosporidiosis outbreaks - United States, 2009-2017. MMWR Morb. Mortal. Wkly. Rep. 68, 568-572.

Giangaspero, A., Papini, R., Marangi, M., Koehler, A.V., Gasser, R.B., 2014 Cryptosporidium parvum genotype IIa and Giardia duodenalis assemblage A in Mytilus galloprovincialis on sale at local food markets. Int. J. Food Microbiol. 171, 62-67.

Goh, S., Reacher, M., Casemore, D.P., Verlander, N.Q., Chalmers, R., Knowles, M., Williams, J., Osborn, K., Richards, S., 2004. Sporadic cryptosporidiosis, North Cumbria, England, 1996-2000. Emerg. Infect. Dis. 10, 1007-1015.

Gomez-Bautista, M., Ortega-Mora, L.M., Tabares, E., Lopez-Rodas, V., Costas, E., 2000 Detection of infectious Cryptosporidium parvum oocysts in mussels (Mytilus galloprovincialis) and cockles (Cerastoderma edule). Appl. Environ. Microbiol. 66, 1866-1870.

Gomez-Couso, H., Mendez-Hermida, F., Castro-Hermida, J.A., Ares-Mazas, E., 2006. Cryptosporidium contamination in harvesting areas of bivalve molluscs. J. Food Prot. 69, 185-190.

Gonzales-Barron, U., Thébault, A., Kooh, P., Watier, L., Sanaa, M., Cadavez, V., 2019. Strategy for systematic review of observational studies and meta-analysis modelling of risk factors for sporadic foodborne diseases. Microbial Risk Anal., 100082.

Haagsma, J.A., Geenen, P.L., Ethelberg, S., Fetsch, A., Hansdotter, F., Jansen, A., Korsgaard, H., O'Brien, S.J., Scavia, G., Spitznagel, H., Stefanoff, P., Tam, C.C., Havelaar, A.H., 2013. Community incidence of pathogen-specific gastroenteritis: reconstructing the surveillance pyramid for seven pathogens in seven European Union member states. Epidemiol. Infect. 141, 1625-1639.

Hagmann, S.H.F., Han, P.V., Stauffer, W.M., Miller, A.O., Connor, B.A., Hale, D.C., Coyle, C.M., Cahill, J.D., Marano, C., Esposito, D.H., Kozarsky, P.E., for the GeoSentinel Surveillance, N., 2014. Travel-associated disease among US residents visiting US Geosentinel clinics after return from international travel. Fam. Pract. 31, 678-687.

Harper, C.M., Cowell, N.A., Adams, B.C., Langley, A.J., Wohlsen, T.D., 2002. Outbreak of Cryptosporidium linked to drinking unpasteurised milk. Commun. Dis. Intell. Q. Rep. 26, 449-450.

Hunter, P.R., 2000. Modelling the impact of prior immunity, case misclassification and bias on case-control studies in the investigation of outbreaks of cryptosporidiosis. Epidemiol. Infect. 125, 713-718.

Hunter, P.R., Nichols, G., 2002. Epidemiology and clinical features of Cryptosporidium infection in immunocompromised patients. Clin. Microbiol. Rev. 15, 145-154.

Kirk, M.D., Pires, S.M., Black, R.E., Caipo, M., Crump, J.A., Devleesschauwer, B., Döpfer, D., Fazil, A., Fischer-Walker, C.L., Hald, T., Hall, A.J., Keddy, K.H., Lake, R.J., Lanata, C.F., Torgerson, P.R., Havelaar, A.H., Angulo, F.J., 2015. World Health Organization estimates of the global and regional disease burden of 22 foodborne bacterial, protozoal, and viral diseases, 2010: a data synthesis. PLoS Med. 12, e1001921.

Kotloff, K.L., Nataro, J.P., Blackwelder, W.C., Nasrin, D., Farag, T.H., Panchalingam, S., Wu, Y., Sow, S.O., Sur, D., Breiman, R.F., Faruque, A.S., Zaidi, A.K., Saha, D., Alonso, P.L., Tamboura, B., Sanogo, D., Onwuchekwa, U., Manna, B., Ramamurthy, T., Kanungo, S., Ochieng, J.B., Omore, R., Oundo, J.O., Hossain, A., Das, S.K., Ahmed, S., Qureshi, S., Quadri, F., Adegbola, R.A., Antonio, M., Hossain, M.J., Akinsola, A., Mandomando, I., Nhampossa, T., Acacio, S., Biswas, K., O'Reilly, C.E., Mintz, E.D., Berkeley, L.Y., Muhsen, K., Sommerfelt, H., Robins-Browne, R.M., Levine, M.M., 2013. Burden and aetiology of diarrhoeal disease in infants and young children in developing countries (the Global Enteric Multicenter Study, GEMS): a prospective, case-control study. Lancet 382, 209-222.

Lange, H., Johansen, O.H., Vold, L., Robertson, L.J., Anthonisen, I.L., Nygard, K., 2014. Second outbreak of infection with a rare Cryptosporidium parvum genotype in schoolchildren associated with contact with lambs/goat kids at a holiday farm in Norway. Epidemiol. Infect. 142, 2105-2113.

Lonigro, A., Pollice, A., Spinelli, R., Berrilli, F., Di Cave, D., Cavallo, P, Brandonisio, O., 2006. Giardia cysts and Cryptosporidium oocysts in membrane-filtered municipal wastewater used for irrigation. Appl. Environ. Microbiol. 72, 7916-7918.

Loury, P., Gross, L., Dugast, F., Favennec, L., Dalle, F., Rougemont, A.d., Polack, B., Giraudeau, D., Valot, S., Costa, D., Hubert, B., 2019. Épidémie de cryptosporidiose dans un collège de l'ouest de la France, November 2017. Bull. Epidémiol. Hebd. 16, 295-300. 
Lucio-Forster, A., Griffiths, J.K., Cama, V.A., Xiao, L., Bowman, D.D., 2010. Minimal zoonotic risk of cryptosporidiosis from pet dogs and cats. Trends Parasitol. 26, 174-179.

Marder, E., 2012. Risk factors for cryptosporidiosis and giardiasis infections in the United States: a case-case comparison in 16 States. Faculty of the Rollins School of Public Health of Emory University.

McKerr, C., Adak, G.K., Nichols, G., Gorton, R., Chalmers, R.M., Kafatos, G., Cosford, P., Charlett, A., Reacher, M., Pollock, K.G., Alexander, C.L., Morton, S., 2015. An outbreak of Cryptosporidium parvum across England \& Scotland associated with consumption of fresh pre-cut salad leaves, May 2012. PLoS ONE 10, e0125955.

Millard, P.S., Gensheimer, K.F., Addiss, D.G., Sosin, D.M., Beckett, G.A., Houck-Jankoski, A., Hudson, A., 1994. An outbreak of cryptosporidiosis from fresh-pressed apple cider. JAMAJAMA 272, 1592-1596.

Moreira, N.A., Bondelind, M., 2017. Safe drinking water and waterborne outbreaks. J. Water Health 15, 83-96.

Moriarty, E.M., McEvoy, J.M., Lowery, C.J., Thompson, H.P., Finn, M., Sheridan, J.J., Blair, I.S., McDowell, D.A., Duffy, G., 2005. Prevalence and characterisation of Cryptosporidium species in cattle faeces and on beef carcases at slaughter. Vet. Rec. 156, 165-168.

Nasser, A.M., 2015. Removal of Cryptosporidium by wastewater treatment processes: a review. J. Water Health 14, 1-13.

Nic Lochlainn, L.M., Sane, J., Schimmer, B., Mooij, S., Roelfsema, J., van Pelt, W., Kortbeek, T., 2019. Risk factors for sporadic cryptosporidiosis in the Netherlands: analysis of a 3-year population based case-control study coupled with genotyping, 2013-2016. J. Infect. Dis. 219, 1121-1129.

Pintar, K.D.M., Pollari, F., Waltner-Toews, D., Charron, D.F., Mcewen, S.A., Fazil, A., Nesbitt, A., 2009. A modified case-control study of cryptosporidiosis (using nonCryptosporidium-infected enteric cases as controls) in a community setting. Epidemiol. Infect. 137, 1789-1799.

Public Health England, 2017. National increase of C. parvum 2015. Final outbreak investigation report (London).

Ravel, A., Nesbitt, A., Pintar, K., Macarthur, A., Wang, H.L., Marshall, B., Pollari, F., 2013. Epidemiological and clinical description of the top three reportable parasitic diseases in a Canadian community. Epidemiol. Infect. 141, 431-442.

Redlinger, T., Corella-Barud, V., Graham, J., Galindo, A., Avitia, R., Cardenas, V., 2002. Hyperendemic Cryptosporidium and Giardia in households lacking municipal sewer and water on the United States-Mexico border. Am. J. Trop. Med. Hyg. 66, 794-798.

Robertson, L.J., Gjerde, B., 2008. Development and use of a pepsin digestion method for analysis of shellfish for Cryptosporidium oocysts and Giardia cysts. J. Food Prot. 71, 959-966.

Robertson, L.J., Temesgen, T.T., Tysnes, K.R., Eikas, J.E., 2019. An apple a day: an outbreak of cryptosporidiosis in Norway associated with self-pressed apple juice. Epidemiol. Infect. 147, e139.

Rosenthal, M., Pedersen, R., Leibsle, S., Hill, V., Carter, K., Roellig, D.M., 2015. Notes from the field: cryptosporidiosis associated with consumption of unpasteurized goat milk - Idaho, 2014. MMWR Morb. Mortal. Wkly. Rep. 64, 194-195.

Rousseau, A., La Carbona, S., Dumetre, A., Robertson, L.J., Gargala, G., Escotte-Binet, S.,
Favennec, L., Villena, I., Gerard, C., Aubert, D., 2018. Assessing viability and infectivity of foodborne and waterborne stages (cysts/oocysts) of Giardia duodenalis, Cryptosporidium spp., and Toxoplasma gondii: a review of methods. Parasite 25, 14.

Roy, S.L., DeLong, S.M., Stenzel, S.A., Shiferaw, B., Roberts, J.M., Khalakdina, A., Marcus, R., Segler, S.D., Shah, D.D., Thomas, S., Vugia, D.J., Zansky, S.M., Dietz, V., Beach, M.J., 2004. Risk factors for sporadic cryptosporidiosis among immunocompetent persons in the United States from 1999 to 2001. J. Clin. Microbiol. 42, 2944-2951.

Ryan, U., Hijjawi, N., Xiao, L., 2018. Foodborne cryptosporidiosis. Int. J. Parasitol. 48, $1-12$.

Ryan, U., Lawler, S., Reid, S., 2017. Limiting swimming pool outbreaks of cryptosporidiosis - the roles of regulations, staff, patrons and research. J. Water Health 15, 1-16.

Troeger, C., Blacker, B.F., Khalil, I.A., Rao, P.C., Cao, S., Zimsen, S.R.M., Albertson, S.B., Stanaway, J.D., Deshpande, A., Abebe, Z., Alvis-Guzman, N., Amare, A.T., Asgedom, S.W., Anteneh, Z.A., Antonio, C.A.T., Aremu, O., Asfaw, E.T., Atey, T.M., Atique, S., Avokpaho, E.F.G.A., Awasthi, A., Ayele, H.T., Barac, A., Barreto, M.L., Bassat, Q.,

Belay, S.A., Bensenor, I.M., Bhutta, Z.A., Bijani, A., Bizuneh, H., Castañeda-Orjuela, C.A., Dadi, A.F., Dandona, L., Dandona, R., Do, H.P., Dubey, M., Dubljanin, E., Edessa, D., Endries, A.Y., Eshrati, B., Farag, T., Feyissa, G.T., Foreman, K.J., Forouzanfar, M.H., Fullman, N., Gething, P.W., Gishu, M.D., Godwin, W.W., Gugnani, H.C., Gupta, R., Hailu, G.B., Hassen, H.Y., Hibstu, D.T., Ilesanmi, O.S., Jonas, J.B., Kahsay, A., Kang, G., Kasaeian, A., Khader, Y.S., Khalil, I.A., Khan, E.A., Khan, M.A., Khang, Y.-.H., Kissoon, N., Kochhar, S., Kotloff, K.L., Koyanagi, A., Kumar, G.A., MagdyaaaaAbdaaaaEl Razek, H., Malekzadeh, R., Malta, D.C., Mehata, S., Mendoza, W., Mengistu, D.T., Menota, B.G., Mezgebe, H.B., Mlashu, F.W., Murthy, S., Naik, G.A., Nguyen, C.T., Nguyen, T.H., Ningrum, D.N.A., Ogbo, F.A., Olagunju, A.T., Paudel, D., Platts-Mills, J.A., Qorbani, M., Rafay, A., Rai, R.K., Rana, S.M., Ranabhat, C.L., Rasella, D., Ray, S.E., Reis, C., Renzaho, A.M.N., Rezai, M.S., Ruhago, G.M. Safiri, S., Salomon, J.A., Sanabria, J.R., Sartorius, B., Sawhney, M., Sepanlou, S.G., Shigematsu, M., Sisay, M., Somayaji, R., Sreeramareddy, C.T., Sykes, B.L., Taffere, G.R., Topor-Madry, R., Tran, B.X., Tuem, K.B., Ukwaja, K.N., Vollset, S.E., Walson, J.L., Weaver, M.R., Weldegwergs, K.G., Werdecker, A., Workicho, A., Yenesew, M., Yirsaw, B.D., Yonemoto, N., ElaaaaSayedaaaaZaki, M., Vos, T., Lim, S.S., Naghavi, M., Murray, C.J.L., Mokdad, A.H., Hay, S.I., Reiner, R.C., 2018. Estimates of the global, regional, and national morbidity, mortality, and aetiologies of diarrhoea in 195 countries: a systematic analysis for the Global Burden of Disease Study 2016. Lancet Infect. Dis. 18, 1211-1228.

Utsi, L., Smith, S.J., Chalmers, R.M., Padfield, S., 2016. Cryptosporidiosis outbreak in visitors of a UK industry-compliant petting farm caused by a rare Cryptosporidium parvum subtype: a case-control study. Epidemiol. Infect. 144, 1000-1009.

Viechtbauer, W., 2010. Conducting meta-analyses in $\mathrm{r}$ with the metafor package. 201036, 48.

Wilson, N., Baker, M., Edwards, R., Simmons, G., 2008. Case-case analysis of enteric diseases with routine surveillance data: potential use and example results. Epidemiol. Perspect. Innov. 5, 6.

Yoshida, H., Matsuo, M., Miyoshi, T., Uchino, K., Nakaguchi, H., Fukumoto, T., Teranaka, Y., Tanaka, T., 2007. An outbreak of cryptosporidiosis suspected to be related to contaminated food, October 2006, Sakai City, Japan. Jpn. J. Infect. Dis. 60, 405-407. 